\title{
Responder por Exclusão em Crianças de 2 a 3 Anos em uma Situação de Brincadeira
}

\author{
Exclusion Responding by 2 to 3 Tear-old Children in a Play Setting \\ Camila Domeniconi*, Aline R. A. Costa, Deisy G. de Souza \& Júlio C. de Rose \\ Universidade Federal de São Carlos, São Carlos, Brasil
}

\begin{abstract}
Resumo
O responder por “exclusão', que se supõe ser um dos mecanismos pelos quais crianças aprendem a relacionar palavras novas a objetos ou eventos, tem sido amplamente replicado em situação de laboratório. O presente estudo, conduzido com seis crianças, teve por objetivo investigar o responder por exclusão em um contex to de brincadeira, com estímulos manipuláveis, e verificar se este contex to favorece a aprendizagem da relação nome - objeto, após uma única tentativa de exclusão. Em cada tentativa o experimentador falava o nome de um brinquedo conhecido e a tarefa da criança era pegá-lo e jogá-lo dentro de uma caixa grande, disposta à frente da criança. Em meio a essas tentativas, eram introduzidas três sondas de exclusão (o nome falado era novo e havia um brinquedo novo exposto no ambiente); três outras sondas verificavam se a relação entre o nome e o brinquedo havia sido aprendida. Todas as crianças responderam por exclusão, mas somente uma mostrou aprendizagem após uma única tentativa.

Palavras-chave: Responder por exclusão; aprendizagem após uma única tentativa; crianças pequenas; situação de brincadeira.

Abstract

Laboratory studies have repeatedly replicated the phenomenon of exclusion responding, which has been assumed as one of the mechanisms by which children learn to relate novel words to objects or events. The present study, conducted with six children, aimed to investigate exclusion responding in a play setting, with stimuli that could be manipulated, and to verify whether the play setting would favor learning of the relationships between names and objects after a single exclusion trial. In several trials the experimenter spoke the name of a familiar toy and the child's task was to pick this toy up and throw it into a box, placed in front of the child. Three exclusion probes were interspersed among these trials (the spoken name was novel and there was a novel toy available); three other probes verified whether the relationships between the novel name and the toy had been learned. All children responded by exclusion but only one of them demonstrated learning the relationships in a single trial.

Key-words: Exclusion responding; one-trial learning; young children; play setting.
\end{abstract}

Um dos aspectos de interesse no estudo da aquisição de vocabulário por crianças durante os primeiros anos de vida diz respeito a como as crianças estabelecem as relações necessárias entre palavras novas e objetos ou eventos para os quais as palavras são empregadas. Estudos naturalísticos da interação mãe-criança registram a ocorrência de episódios em que a criança procura sistematicamente por alguma coisa nova ou diferente no ambiente, quando o adulto fala uma palavra com a qual ela não está familiarizada (e.g., Bates, 1979; Volterra, Bates, Benigni, Bretherton, \& Camaioni, 1979). Esse processo tem sido sistematicamente reproduzido

\footnotetext{
* Endereço para correspondência: Alameda das Tulipas, 253, Dourado, SP, 13590-000. Fones: (Oxx16) 3345-3491; $3351-8492$ (fone/fax). E-mail: camila@power.ufscar.br

Esta pesquisa contou com apoio financeiro do PRONEX/FAPESP (Processo número 03/09928-4), com bolsa de doutorado CAPES para C. D., bolsa de doutorado FAPESP para A. R. A. C. e bolsa de Produtividade em Pesquisa do CNPq para D. G. S. e J. C. R. Os autores agradecem a revisão cuidadosa e as sugestões de dois revisores anônimos que contribuíram para o aprimoramento do texto.
}

em situação de laboratório com uma preparação experimental que emprega uma tarefa simples, de escolha de acordo com o modelo. Nesta tarefa, o experimentador dita uma palavra e a criança escolhe, entre dois ou mais itens apresentados simultaneamente, o objeto ou figura correspondente. Em geral, a tarefa começa com palavras que a criança já conhece (palavras definidas), como por exemplo, "Pegue a boneca" ou "Mostre o au-au". Ao longo das tentativas, o experimentador introduz uma palavra nova (ou indefinida experimentalmente), geralmente uma pseudo-palavra, como por exemplo, "Pegue o zagü’. Nessa situação, invariavelmente, a criança tende a escolher, entre os estímulos de comparação, um que seja "novo" ou diferente dos que ela já relaciona a outras palavras (Bates \& Snyder, 1988; Carey \& Bartlett, 1978; Costa, Wilkinson, McIlvane, \& de Souza, 2001; Wilkinson \& McIlvane, 1997). Esse tipo de escolha tem sido chamado de "responder por exclusão", na Análise do Comportamento e de “mapeamento rápido” na Psicolingüística. 
Apesar das diferentes interpretações pelas duas abordagens, ambas tem contribuído para o esclarecimento de condições para a escolha por exclusão ao longo de mais de vinte anos de pesquisas (McIlvane, Wilkinson, \& de Souza, 2000; Wilkinson \& McIlvane, 1997), nas quais a ocorrência desse comportamento tem sido extensivamente documentada e replicada, com diferentes populações de crianças, de diferentes idades e nacionalidades, seja com desenvolvimento típico ou com atrasos de desenvolvimento (Carey \& Bartlet, 1978; Costa et al., 2001; Dixon, 1977; Dixon, Dixon, \& Spradlin, 1983; Golinkoff, Hirsh-Pasek, Bailey, \& Wenger, 1992; Golinkoff, Mervis, \& Hirsh-Pasek, 1994; Markman, 1989, entre outros). Além disso, também foi demonstrada a escolha por exclusão mesmo na ausência de palavras: depois que um indivíduo aprende a relacionar pares de estímulos visuais abstratos, se um novo estímulo é apresentado como modelo, em uma tarefa de emparelhamento, e se há um estímulo novo entre as alternativas de escolha, esse é o estímulo escolhido, quer o participante de pesquisa seja um estudante universitário (McIlvane, Kledaras, Munson, King, de Rose, \& Stoddard, 1987), ou uma criança (Oshiro, 2004).

Dois conjuntos de explicações têm sido apontados para esse padrão de comportamento. Segundo uma dessas explicações (Dixon, 1977; Markman, 1987), o desempenho observado seria resultado de uma rejeição dos estímulos conhecidos (definidos experimentalmente) diante do nome novo (ou indefinido). Outra explicação é a de que a criança relaciona diretamente a palavra falada e o objeto que são novos, independentemente dos outros objetos presentes; nesse caso, a relação importante, e que determina a escolha, é a propriedade que ambos os eventos compartilham, isto é, tanto o "nome" quanto o objeto são novos. Essa é a concepção denominada pela Análise do Comportamento de "relação de controle pelo S+", para expressar controle relacional entre o estímulo modelo (a palavra falada) e o estímulo de comparação indefinido (Dixon, Dixon, \& Spradlin, 1983), e que recebe, na psicolingüística, o título descritivo de nome novo-categoria sem nome (Golinkoff et al., 1992), isto é, para um novo nome, alguma coisa que ainda não tem nome, deve ser identificada.

Explicações alternativas, embora pareçam opostas, podem, de fato, ser complementares e no caso do responder por exclusão não foi diferente. Diante da dificuldade em se identificar empiricamente se um participante de pesquisa estaria respondendo "por exclusão" de alguns estímulos ou por uma relação direta entre uma palavra falada e um estímulo novo, Wilkinson e McIlvane (1997) desenvolveram um procedimento que permite separar experimentalmente esses tipos de controle. O procedimento consiste em empregar simultaneamente duas ou mais alternativas de escolha, mas uma delas é uma espécie de "máscara” ou janela vazia, enquanto a outra apresenta um estímulo convencional. No exemplo "Aponte a boneca", com duas escolhas, um dos estímulos de escolha seria necessariamente a "máscara”, enquanto o outro poderia ser a figura de uma boneca ou a de um ursinho de brinquedo. Se fosse a figura da boneca, esta seria a escolha correta; porém, se fosse a figura do urso, a criança aprenderia a apontar a máscara (como se a figura da boneca estivesse escondida sob a máscara). Essa alternativa transforma a tarefa de escolha em uma tarefa do tipo "sim" ou "não" para o estímulo de escolha: "sim, esta é a boneca”; ou "não, esta não é a boneca”. Segundo Wilkinson e McIlvane (1997), esse procedimento permitiria que o participante rejeitasse ambos os estímulos: tanto o estímulo de comparação definido (a figura previamente conhecida), como o indefinido (a figura "nova”), na presença de um modelo indefinido (palavra falada desconhecida). Nesse caso, se ainda assim o indivíduo selecionasse o estímulo de comparação indefinido, isto seria forte evidência de que estaria relacionando os estímulos indefinidos (a palavra falada e o objeto) de acordo com a regra da novidade (relação de controle pelo $\mathrm{S}+$ ). Por outro lado, se selecionasse a janela vazia, isto enfraqueceria a noção de que a relação controladora seria a de seleção do $\mathrm{S}+$.

O procedimento foi implementado por Wilkinson e McIlvane (1997- Experimento 1) por meio de um micro computador equipado com tela sensível ao toque para apresentação dos estímulos de comparação. O experimentador apresentava, inicialmente, um estímulo modelo auditivo (a palavra casa, ou árvore ou cachorro); os estímulos de comparação eram as três figuras correspondentes. A máscara era então introduzida sobre um dos estímulos de comparação, começando como um pequeno quadrado preto, que aumentava gradualmente ao longo de 16 tentativas sucessivas, até cobrir completamente uma das figuras. Desse modo, ao final dessa etapa do procedimento ficavam disponíveis duas figuras e o quadrado preto. O quadrado cobria um dos estímulos comparação negativo em metade das tentativas e o positivo na outra metade. Depois que o desempenho de selecionar ora uma figura, ora a máscara estava bem estabelecido (linha de base)eram introduzidas sondas (tentativas de teste) para verificar o que a criança faria diante de pseudopalavras. Cada sessão tinha 30 tentativas; 28 eram tentativas de linha de base e duas eram tentativas de sonda. A primeira sonda era apresentada entre as primeiras 15 tentativas; a palavra ditada era "pafe" e os estímulos de comparação eram uma figura definida (casa, árvore ou cachorro), uma figura nova e a máscara. A segunda sonda era uma tentativa controle para o responder na máscara, apresentada entre as últimas 15 tentativas; a palavra ditada era " $x e d e$ e os estímulos de comparação eram duas das figuras conhecidas e a máscara. Na primeira tentativa de sonda, todas as oito crianças do estudo selecionaram o estímulo de comparação novo. Na segunda tentativa de sonda, todos os participantes selecionaram a máscara. Segundo os autores, o primeiro resultado favorece a hipótese de que a estratégia empregada teria sido a seleção da Novidade $\mathrm{S}+$, pois as crianças tinham outras opções (um estímulo de comparação conhecido e a máscara) além do estímulo de comparação novo que todas escolheram, confirmando os dados de outros estudos de que, frente a um nome novo e um estímulo novo, as crianças sistematicamente selecionam o objeto (estímulo) novo, não importando quais sejam as outras opções. Se as crianças estivessem apenas rejeitando o estímulo definido, suas respostas poderiam se distribuir aleatoriamente entre 
o quadrado e o estímulo novo. No entanto, a segunda sonda mostrou claramente que eles também podiam responder por exclusão, pois rejeitaram duas outras comparações conhecidas e selecionaram a máscara que, supostamente, ocultava a comparação desconhecida.

De acordo com McIlvane et al. (2000) o responder por exclusão é tão robusto exatamente porque os dois tipos de relações de controle (por seleção e por rejeição) podem se desenvolver, prevalecendo, sob a situação de sonda, aquele que for possível diante das alternativas de escolha.

Uma outra questão muito importante é se o fato de fazer a relação uma vez (seja por seleção, seja por exclusão) significa que a criança tenha aprendido a relação (ou que a relação tenha sido estabelecida no repertório do aprendiz). Segundo Golinkoff et al. (1994), e Markman (1989), a aprendizagem dessas relações seria possível, em tese, mesmo após uma única exposição da relação entre o nome e o objeto correspondente.

Wilkinson e McIlvane (1997- Experimento 2) investigaram empiricamente suposição de que poderia ocorrer aprendizagem após uma única tentativa de exclusão. O procedimento foi idêntico ao do Experimento 1, com o mesmo grupo de crianças, exceto pelo uso de novos estímulos indefinidos. Após a revisão da linha de base com três comparações foram realizadas três sessões de 30 a 36 tentativas, duas das quais eram tentativas de sonda. Em cada sessão, a primeira tentativa de sonda (realizada entre a primeira metade das tentativas) era uma tentativa de exclusão. A segunda tentativa de sonda (realizada entre a última metade das tentativas) visava verificar a ocorrência de aprendizagem que foi testada por meio de diferentes composições da matriz de estímulos de comparação. Para ilustrar, pode-se tomar como exemplo um conjunto hipotético de nomes indefinidos: A1, A2, A3, A4, A5 e de estímulos visuais indefinidos B1, B2, B3, B4, B5 e B6. Após as sondas em que foram emparelhadas, uma única vez, por exclusão, os pares A1B1 (na sessão 1), A3B3 (na sessão 2) e A5B5 (na sessão 3), foram testados três tipos diferentes de sondas para verificação da aprendizagem: Sondas de Resultado 1- A2 (novo) como estímulo modelo e B1 (relacionado com A1 na primeira sonda) como estímulo de comparação, juntamente com a máscara e um estímulo definido, por exemplo, uma casa (correspondendo ao Teste de Resultado 3 de Wilkinson \& McIlvane, 1997); Sondas de Resultado 2A4 (novo) como estímulo modelo e como estímulos de comparação B3 (relacionado com A3 na primeira sonda), B4 (outro novo) e a máscara (correspondendo ao Teste de Resultado 2 , naquele estudo); e Sondas de Resultado 3- A5 como modelo (o mesmo nome utilizado na primeira sonda dessa sessão), e como estímulos de comparação B6 (novo), um estímulo definido anteriormente e a máscara (correspondendo ao Teste de Resultado 4). Com essas manipulações, ora no nome ditado, ora na figura apresentada, os autores visavam verificar se as relações adquiridas entre um nome e uma figura, após a única tentativa em que foram relacionadas (na primeira sonda), de fato geraram aprendizagem a ponto de a criança rejeitar o estímulo já relacionado a cada nome (na Sonda de Resultado 1), selecionar um estímulo novo diante de um segundo nome novo mesmo na presença do estímulo que era "novo" na primeira sonda (na Sonda de Resultado 2), ou ainda se, diante de um mesmo nome relacionado a uma figura na sonda anterior, "resistiria" à novidade do segundo estímulo novo e escolheria a máscara (na Sonda de Resultado 3). Os resultados mostraram uma grande variabilidade nessas sondas, indicando que provavelmente uma tentativa não é suficiente para que o participante aprenda uma nova relação nome-objeto.

Esses resultados foram replicados por Costa et al. (2001), com crianças brasileiras na faixa etária dos três aos 13 anos, confirmando, por um lado, a robustez do responder por exclusão na primeira sonda e, por outro lado, uma grande variabilidade nas sondas de aprendizagem, uma vez que poucas crianças apresentaram responder consistente com a hipótese de aprendizagem nos três tipos de sondas, embora tenham apresentado esse tipo de desempenho em uma ou em duas delas.

Esses estudos foram conduzidos em situação experimental com a tarefa de emparelhamento com o modelo apresentada por intermédio do computador. Considerando-se que o contex to em que a tarefa é realizada pode ter um importante papel nos resultados experimentais (Carraher \& Spinilo, 1989), o presente estudo teve como objetivo verificar se a realização da tarefa em situação de brincadeira poderia facilitar a aprendizagem de relação nome-objeto, após uma única tentativa de exclusão.

\section{Método}

\section{Participantes}

Participaram do estudo seis crianças entre 24 e 36 meses de idade, todos sem queixa quanto a atraso no desenvolvimento motor, atraso no desenvolvimento da linguagem, perda auditiva ou deficiência visual. A Tabela 1 apresenta informações sobre idade e sexo dos participantes.

$\mathrm{O}$ recrutamento dos participantes foi feito por contato direto com as famílias. Ao solicitar a autorização para a participação no estudo era dito ao responsável que o trabalho versava sobre aquisição de vocabulário e que o procedimento constaria de uma brincadeira. Ainda era esclarecido que o procedimento seria realizado em três sessões, em três dias consecutivos (cada sessão em um dia). Quando o

Tabela 1

Nomes dos Participantes (Fictícios) e Respectivas Idades (em Meses) na Ocasião do Estudo e Escores Obtidos no Peabody Picture Vocabulary Test-revised (Dunn \& Dunn, 1981)

\begin{tabular}{lcc}
\hline $\begin{array}{l}\text { Nome do } \\
\text { participante } \\
\text { (fictício) }\end{array}$ & $\begin{array}{c}\text { Idade em } \\
\text { meses } \\
\text { (cronológica) }\end{array}$ & $\begin{array}{c}\text { Idade em } \\
\text { meses } \\
\text { PPPv-T) }\end{array}$ \\
\hline Nara & 25 meses & 24 meses \\
Ana & 26 meses & 22 meses \\
Juliana & 29 meses & 30 meses \\
Lilian & 30 meses & 30 meses \\
Bruno & 32 meses & 36 meses \\
Tiago & 34 meses & 36 meses \\
\hline
\end{tabular}


pai ou responsável autorizava a participação de uma criança, ele era solicitado a formalizar a autorização por escrito, em um formulário.

\section{Situação e Equipamento}

As sessões foram realizadas individualmente, em três dias consecutivos, em uma sala silenciosa, apropriada para este fim, contendo duas grandes janelas, um espelho com visão unidirecional e um armário embutido em uma das quatro paredes.

Para a realização das sessões foram utilizados: um tapete, uma caixa grande, cinco brinquedos conhecidos: uma boneca, um peixe, um caminhão, um avião, um carro e uma bola, cinco brinquedos desconhecidos (inventados e construídos com sucata pelo experimentador), uma caixa grande de papelão e três caixas pequenas. A caixa grande serviu como recipiente onde os brinquedos eram depositados pelas crianças como parte da brincadeira. As caixas pequenas tinham a função similar às máscaras utilizadas nos procedimentos via computador, ou seja, os brinquedos poderiam ser guardados dentro destas caixas pequenas, não ficando expostos no momento da brincadeira.

As sessões eram filmadas por uma câmera (Panasonic OmniMovie VHS PV-950), fixada ao lado esquerdo do participante, de modo a focalizar a criança, os brinquedos, a caixa grande e as três caixas pequenas.

O registro do desempenho das crianças nas tentativas de escolha foi realizado por meio da análise das filmagens. Dois experimentadores assistiram às filmagens, independentemente e depois conferiam se havia concordância sobre o desempenho dos participantes. Tendo em vista que a resposta de interesse é bastante clara e bem definida, não foram encontrados casos de discordância nos registros.

Os estímulos utilizados como modelo foram nomes definidos e nomes indefinidos, ditados pelo experimentador; os estímulos de comparação foram os brinquedos definidos listados acima e os indefinidos (criados pelo experimentador). Por conveniência na descrição, os termos nomes indefinidos e brinquedos indefinidos serão empregados até o final do presente texto, significando estímulos inventados pelo experimentador (tanto as pseudo palavras quanto os objetos), ou seja, não conhecidos pela criança até a participação no experimento; ao contrário, nomes e brinquedos definidos, no presente texto, se referirão aos brinquedos familiares de uso comum das crianças pequenas, cujos nomes também já são bastante familiares, estando bem estabelecida a relação entre o brinquedo e seu nome na história pré-experimental das crianças. Os nomes indefinidos utilizados como estímulos modelo foram: capiru, darga, jatir, sevina e fulito e os nomes definidos foram: boneca, peixe, caminhão, avião, carro e bola.

\section{Procedimento}

Fase 1- Estabelecimento das discriminações condicionais: emparelhamento auditivo visual. A tarefa consistia em localizar e pegar um brinquedo, entre outros expostos ou guardados em caixas fechadas, assim que o experimentador dissesse o nome do brinquedo.
No início do primeiro dia de sessão com cada criança, foram realizadas dez tentativas de linha de base para estabelecer o repertório de selecionar um dos brinquedos, condicionalmente ao nome falado pelo experimentador, e jogálo na caixa grande. A instrução consistia em: "Pegue a bola... Vamos jogá-la na caixa grande para ouvir o barulhão que ela vai fazer?” Quatro brinquedos eram dispostos ao lado da criança, no chão e dois dos brinquedos eram colocados dentro de duas das três caixas pequenas. Todos os objetos ficavam no chão, sobre o tapete, próximos à criança. A colocação de dois brinquedos dentro das caixas pequenas tinha o objetivo de incluir as caixas na brincadeira como estímulos relevantes para a criança. Ao verificar que nem todos os brinquedos solicitados estavam expostos, a criança aprendia que existiam estímulos dentro das caixas (similar ao treino de uso da máscara com função de $\mathrm{S}+$ e S- no procedimento computadorizado).

Depois de ditar o nome de cada um dos cinco brinquedos definidos (peixe, bola, caminhão, avião e boneca), o experimentador reorganizava os brinquedos e ditava os nomes, em uma outra seqüência. Ao recolocar os estímulos, para início de uma nova tentativa, a localização deles variava a fim de não influenciar a aquisição das discriminações. O conjunto de estímulos totalizava oito itens, três caixas pequenas e cinco brinquedos familiares. Durante a sessão, procurava-se garantir a permanência de pelo menos cinco alternativas de escolha, ou seja, ao longo da brincadeira um dos experimentadores retirava alguns objetos da caixa grande e os redistribuía no tapete a fim de disponibilizá-los como estímulos de comparação e manter um número mínimo de comparações; um dos brinquedos era colocado sempre dentro das caixas e esta era a escolha correta em metade das tentativas. Era requerido um critério de 100\% de acertos para passar para a próxima fase; enquanto o critério não fosse atingido, o bloco com dez tentativas continuava sendo apresentado, até o limite de três apresentações (ou 30 tentativas) por sessão. As sessões continuavam sendo realizadas até que o critério fosse atingido.

O experimentador apresentava conseqüências diferenciais para as respostas corretas e incorretas. Assim que o brinquedo definido como correto para aquela tentativa (ou seja, o brinquedo correspondente ao nome definido falado pelo experimentador) caia dentro da caixa grande, o experimentador reproduzia o som do brinquedo ao cair, algo do tipo: "Buuum". Além disso, o experimentador batia palmas e apresentava reforços sociais por meio de verbalizações como: “Muito bom!”, “Jóia!”, “Que legal!”, "Isto mesmo!", “Olha, caiu!”. As respostas incorretas eram seguidas pela seguinte fala do experimentador: "Não é este, espere, vamos ouvir qual é o brinquedo que vamos jogar”. O experimentador emitia esta resposta e segurava delicadamente as mãos da criança antes que ela jogasse o brinquedo na caixa grande; então, ele esperava que o participante colocasse o brinquedo de volta entre os outros brinquedos e ditava novamente o nome do brinquedo. Este era um procedimento de correção e a tentativa não era contabilizada como uma tentativa completa (já que não 
havia a colocação do brinquedo na caixa grande), ou seja, as dez tentativas contabilizadas como constituintes da linha de base eram tentativas completas, com a escolha condicional do brinquedo pedido pelo experimentador e a colocação dele na caixa grande. Tentativas em que o procedimento de correção era empregado eram registradas como erro.

Fase 2-Sondas de Exclusão. O primeiro bloco de testes era realizado logo após estabelecimento da linha de base de discriminações condicionais. O bloco de teste consistia de duas tentativas de sondas inseridas em um bloco de dez tentativas de linha de base. A primeira sonda (de exclusão), apresentada entre as cinco primeiras tentativas de linha de base, verificava se, diante de um nome indefinido, ditado pela primeira vez, os participantes selecionariam um brinquedo indefinido disponível, um brinquedo definido ou se procurariam por algum item diferente, dentro das caixas pequenas (que tiveram função similar à das máscaras dos procedimentos computadorizados). A segunda tentativa de sonda, apresentada entre as cinco últimas tentativas de linha de base, permitia verificar possíveis efeitos de aprendizagem na primeira sonda (ver descrição detalhada das tentativas de sonda na caracterização dos Tipos de sonda a seguir).

As consequências diferenciais para respostas corretas e incorretas eram as mesmas apresentadas nos blocos de treino para o estabelecimento das discriminações condicionais auditivo visuais.

Foram conduzidos três blocos de testes, acumulando um total de seis tentativas de sondas, três de exclusão e três de verificação de aprendizagem. Os blocos de testes eram realizados em três dias consecutivos: Tentativas de sondas Tipo 1 no primeiro dia, Tentativas de sondas Tipo 2 no segundo dia, e Tentativas de sondas Tipo 3 no terceiro dia. A Figura 1 apresenta os três tipos de sondas, os estímulos modelo ditados em cada uma delas, os estímulos de comparação simultaneamente disponíveis e as respostas esperadas nas duas sondas de cada tipo.

\section{Tentativas de Sondas Tipo 1}

Na primeira tentativa de sonda de Tipo 1, entre as cinco primeiras tentativas de linha de base, era ditado como modelo o nome indefinido "Capiru" e os estímulos de com-

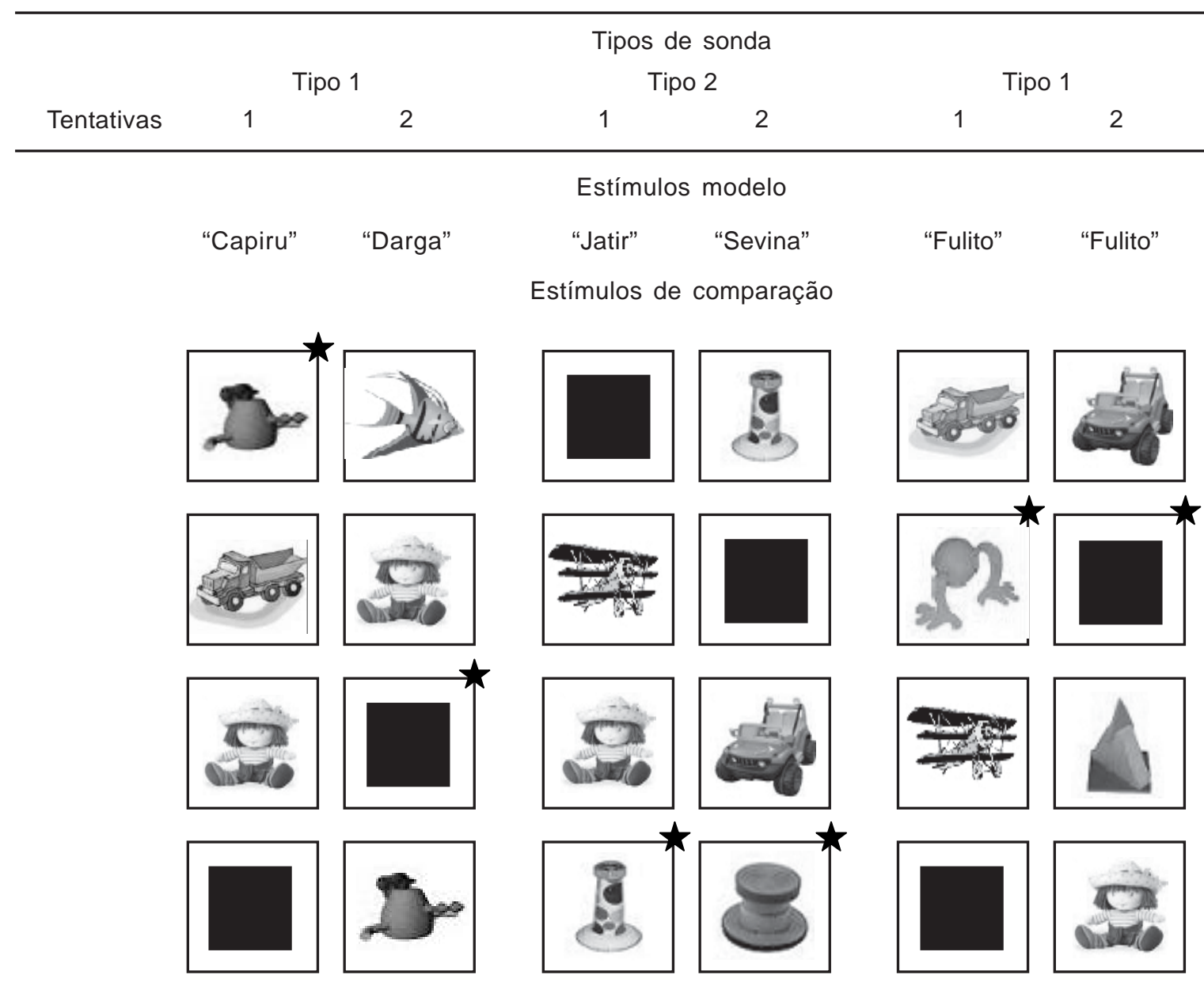

Figura 1. Características dos três tipos de sonda: estímulos modelo, amostra de estímulos de comparação empregados em cada sonda e respostas indicativas de exclusão na primeira tentativa e de aprendizagem na segunda tentativa. Em cada tentativa o arranjo de estímulos de comparação incluía e quatro ou cinco estímulos, entre os quais um ou dois indefinidos 
paração eram os cinco brinquedos definidos, um brinquedo indefinido $\left(I_{1}\right)$ e as caixas pequenas, sendo que um dos brinquedos definidos era aleatoriamente colocado dentro de uma das três caixas pequenas. A resposta experimentalmente definida como correta (exclusão) seria a escolha pela criança do brinquedo indefinido.

Entre as últimas cinco tentativas de linha de base ocorria a segunda tentativa de sonda (verificação de aprendizagem) e o nome ditado era "Darga". Os estímulos de comparação eram as caixas pequenas, quatro brinquedos conhecidos e o brinquedo $\mathrm{I}_{1}$, já apresentado na primeira tentativa de sonda deste bloco de teste. Dentro de uma das caixas pequenas estava colocado um outro brinquedo indefinido inteiramente novo $\left(\mathrm{I}_{2}\right)$. A colocação deste brinquedo na caixa tinha a função de dar continuidade à brincadeira, caso a criança de fato procurasse por um brinquedo inteiramente novo, rejeitando o I e demonstrando indícios de aprendizagem da relação entre o nome e o brinquedo $\mathrm{I}_{1}$, após uma única tentativa em que estes foram relacionados.

A escolha do brinquedo $\mathrm{I}_{1}$ (supostamente definido na primeira tentativa de sonda) indicaria ou que o participante aceitava dois nomes para um mesmo brinquedo ou que não teria ocorrido aprendizagem após uma única tentativa de exclusão. Caso a criança buscasse por outro brinquedo nas caixas pequenas (o que corresponderia a selecionar a máscara no procedimento computadorizado), isso indicaria que ela aprendeu a relação entre o primeiro brinquedo indefinido $\left(\mathrm{I}_{1}\right)$ e o nome "Capiru”, mesmo após uma única tentativa de exclusão (e que agora, na segunda tentativa, rejeitava "Darga" como nome daquele mesmo estímulo e buscava por outro, novo, que correspondesse ao novo nome).

\section{Tentativas de Sondas Tipo 2}

$\mathrm{Na}$ primeira tentativa de sonda de Tipo 2 o estímulo modelo ditado era o nome indefinido: "Jatir" e os estímulos de comparação eram três ou quatro brinquedos definidos, um terceiro brinquedo indefinido $\left(\mathrm{I}_{3}\right)$, e as caixas pequenas (uma das quais continha um dos brinquedos definidos). A resposta da criança que indicaria um resultado positivo neste teste de exclusão seria a seleção do brinquedo indefinido $\mathrm{I}_{3}$.

Na segunda tentativa de sonda Tipo 2 visando verificar se a relação entre o nome "Jatir" e o brinquedo indefinido I havia sido aprendida, era apresentado o nome "Sevina" como modelo; os estímulos de comparação eram as caixas, os brinquedos definidos, o brinquedo indefinido $\mathrm{I}_{s}$, já apresentado na tentativa 1 e um outro completamente novo $\left(\mathrm{I}_{4}\right)$. Uma das caixas pequenas continha um dos brinquedos definidos. A questão a ser testada nesta segunda tentativa de sonda era se o participante atribuiria um nome novo ("Sevina”) a um estímulo $\left(\mathrm{I}_{3}\right)$ se já tivesse atribuído a ele o nome "Jatir" na primeira tentativa de sonda, ou se escolheria outro estímulo ( $\mathrm{I}_{4}$ ou a máscara). Portanto, considerando que o participante já tivesse relacionado o nome "Jatir" com o brinquedo indefinido $\mathrm{I}_{s}$, uma resposta que indicaria aprendizagem desta relação, seria a escolha do brinquedo indefinido $\mathrm{I}_{4} \mathrm{Ou}$ de uma das caixas pequenas.

\section{Tentativas de Sonda Tipo 3}

Neste tipo de sonda um mesmo nome indefinido, "Fulito", era ditado como modelo tanto na Tentativa de sonda 1 (exclusão) quanto na Tentativa 2 (resultado de aprendizagem).

$\mathrm{Na}$ primeira sonda os estímulos de comparação eram os brinquedos definidos, um brinquedo indefinido $\left(\mathrm{I}_{5}\right)$ e as caixas pequenas (uma delas contendo um brinquedo definido); na segunda sonda os estímulos de comparação eram os brinquedos definidos, um brinquedo indefinido $\left(\mathrm{I}_{6}\right)$ e as caixas pequenas (uma delas contendo o brinquedo $\mathrm{I}_{5}$ ).

Neste tipo de sonda, enquanto a primeira tentativa, mais uma vez, consistia em uma sonda de exclusão, a segunda tentativa verificava se diante do mesmo nome indefinido que havia sido ditado na sonda anterior o participante selecionaria o brinquedo $\left(\mathrm{I}_{6}\right)$, o único indefinido exposto entre as comparações ou se, no caso de ter aprendido a relação entre o nome indefinido "Fulito" e o brinquedo $\mathrm{I}_{5}$, o procuraria dentro de uma das caixas pequenas.

\section{Resultados}

\section{Estabelecimento das Discriminações Condicionais por Emparelhamento Auditivo Visual}

Todos os participantes atingiram 100\% de respostas corretas no bloco de tentativas de linha de base, na segunda apresentação. Isto significa que, em uma única sessão, todas as crianças passaram a ficar sob controle condicional dos estímulos modelo ditados pelo experimentador ao fazerem as escolhas dos brinquedos a serem jogados na caixa grande, estando os brinquedos expostos ou guardados nas caixas pequenas.

\section{Blocos de Teste}

A primeira tentativa de sonda nesses testes investigou a ocorrência do responder por exclusão. Todos os participantes escolheram o brinquedo indefinido quando o nome indefinido era ditado. Portanto, todos responderam por exclusão nas tentativas planejadas para avaliar esse desempenho. Os resultados da verificação da aprendizagem da relação nome-objeto, realizada na segunda tentativa de cada tipo de sonda são apresentados na Tabela 2 e descritos a seguir.

\section{Tentativas de Sondas Tipo 1}

Esta sonda foi realizada com o intuito de verificar se um participante que havia escolhido um brinquedo indefinido $\left(\mathrm{I}_{1}\right)$ diante da "Capiru" selecionaria novamente o mesmo brinquedo quando um novo nome, "Darga", fosse ditado, ou se procuraria por um brinquedo totalmente novo $\left(\mathrm{I}_{2}\right)$ no ambiente, o que corresponderia a um desempenho indicativo de aprendizagem (ver Figura 1). Dois participantes (Bruno e Nara) escolheram o mesmo brinquedo anteriormente relacionado ao estímulo "Capiru” e os outros quatro (Juliana, Tiago, Ana e Lilian) procuraram por algo dentro das caixas pequenas, resposta similar à escolha pela máscara nos procedimentos computadorizados (ver Tabela 2). 
Tabela 2

Seleções de cada Participante (V) na Segunda Tentativa de Verificação de Aprendizagem em cada Tipo de Sonda. Os Dígitos ao Lado do Nome Fictício de cada Participante Indicam sua Idade em Meses

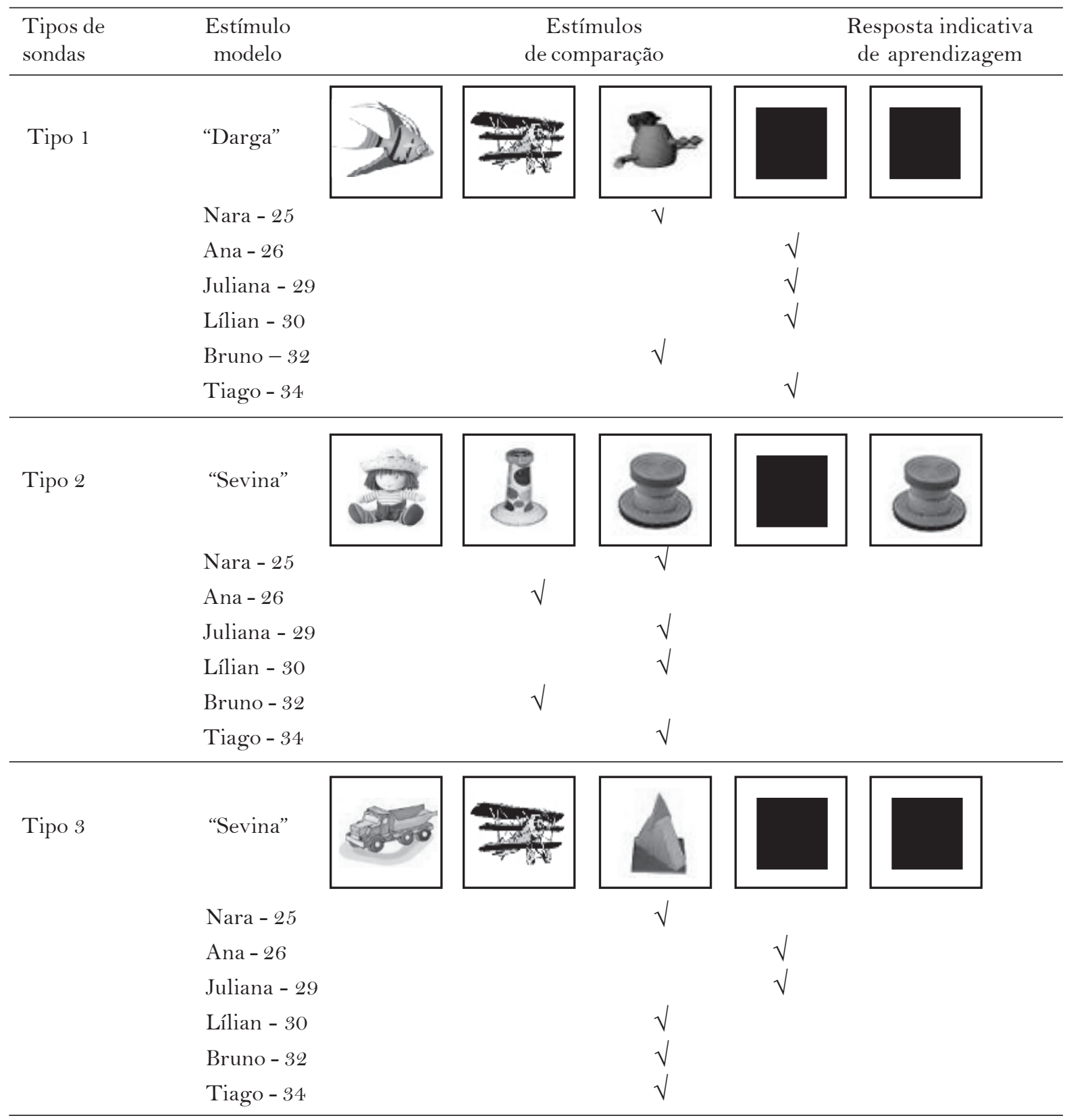

\section{Tentativas de Sondas Tipo 2}

Na segunda sonda desse tipo, foi apresentado um modelo auditivo, "Sevina”, e os estímulos de comparação eram dois ou três brinquedos definidos, um brinquedo indefinido $\left(\mathrm{I}_{3}\right)$ que havia sido apresentado na primeira sonda deste mesmo bloco (quando o modelo auditivo havia sido a palavra "Jatir"), um novo brinquedo indefinido $\left(\mathrm{I}_{4}\right)$ e as caixas pequenas. Este teste visava verificar se um participante que acabara de selecionar um brinquedo indefinido diante do nome "Jatir", escolheria o mesmo brinquedo $\left(\mathrm{I}_{3}\right)$ diante de outro nome indefinido ("Sevina”) ou se escolheria outro brinquedo totalmente indefinido $\left(\mathrm{I}_{4}\right)$.
Dois dos participantes (Bruno e Ana) escolheram o mesmo brinquedo nas duas tentativas de sonda, ou seja, diante de dois nomes diferentes, escolheram o mesmo brinquedo; os outros quatro participantes (Lilia, Nara, Juliana e Tiago) escolheram o brinquedo completamente novo quando um segundo nome foi ditado (Tabela 2).

\section{Tentativas de Sondas Tipo 3}

Esta tentativa de sonda visava investigar se, diante do mesmo nome relacionado ao brinquedo indefinido $\mathrm{I}_{5}$ na Tentativa 1, mas não disponível entre os estímulos de comparação à vista, os participantes escolheriam outro brin- 
quedo indefinido ( $\mathrm{I}_{6}-$ não relacionado experimentalmente a nenhum nome) ou se procurariam por $I_{5}$ dentro das caixas pequenas. Dos seis participantes, quatro (Bruno, Nara, Lilian e Tiago) escolheram o brinquedo completamente novo diante do mesmo nome "Fulito" já relacionado a um outro brinquedo na tentativa de sonda anterior (como mostra a Tabela 2), o que indica não aprendizagem. Os outros dois (Juliana e Ana) aprenderam a relação na Tentativa 1, uma vez que nesta segunda tentativa procuraram por algum brinquedo dentro das caixas.

No conjunto, os resultados da verificação de aprendizagem mostram que, entre as seis crianças participantes do estudo, apenas Juliana demonstrou aprendizagem consistente, após uma única tentativa de exclusão nos três tipos de sondas que foram aplicadas. Nas sondas Tipo 1, após ter relacionado um brinquedo indefinido ao nome "Capiru", ela procurou por algo novo dentro das caixas pequenas quando foi ditado um segundo nome indefinido "Darga" e o brinquedo I estava disponível no ambiente. Além de Juliana, outras três crianças (Lilian, Ana e Tiago) fizeram esta mesma escolha, considerada experimentalmente como a escolha correta. Nara e Bruno, no entanto, escolheram o mesmo brinquedo da tentativa anterior, demonstrando que não aprenderam a relação estabelecida em apenas uma tentativa de exclusão. Nas sondas Tipo 2, Juliana e outras três crianças (Nara, Lilian e Tiago) escolheram um brinquedo indefinido totalmente novo $\left(\mathrm{I}_{4}\right)$ diante de um nome indefinido novo (Sevina), rejeitando o brinquedo $\left(\mathrm{I}_{s}\right)$ anteriormente relacionado a um outro nome (Jatir); os dois brinquedos, $\mathrm{I}_{3 \mathrm{e}} \mathrm{I}_{4}$ estavam disponíveis no ambiente junto com brinquedos definidos e as caixas. Finalmente, nas sondas Tipo 3, a escolha definida como correta e indicativa de aprendizagem seria a escolha de uma das caixas pequenas, indicando a busca pelo brinquedo anteriormente relacionado a "Fulito" $\left(\mathrm{I}_{5}\right.$, $\mathrm{O}$ brinquedo que todas as crianças selecionaram diante desse mesmo nome), mas que não se encontrava à vista. Juliana e Ana procuraram nas caixas pequenas diante da apresentação do mesmo nome "Fulito", mas as outras quatro crianças selecionaram um brinquedo indefinido totalmente novo, $\mathrm{I}_{6}$, indicando que não aprenderam a relação entre I $\mathrm{e}$ "Fulito" na tentativa anterior de exclusão. Portanto, uma única criança demonstrou aprendizagem consistente nos três tipos de sondas; três demonstraram aprendizagem em duas das sondas; uma em apenas uma e outra não demonstrou aprendizagem.

\section{Discussão}

O presente estudo teve o objetivo de investigar a ocorrência de exclusão em crianças pequenas, com o uso de estímulos manipuláveis e funcionais em um contexto de brincadeira. A partir da sugestão de Carraher e Spinilo (1989), de que o contex to em que a tarefa é realizada pode ter um importante papel nos resultados experimentais, objetivouse investigar se essa variação no contex to seria mais favorável que os procedimentos de discriminação condicional, realizados por intermédio do computador, à aprendizagem da relação entre nomes indefinidos e objetos após uma única tentativa de exclusão em que cada par foi relacionado.
A utilização de uma adaptação do procedimento de máscara desenvolvido por Wilkinson e McIlvane (1997), por meio de caixas onde um brinquedo ficava guardado (oculto), permitiu também uma análise preliminar sobre o tipo de controle envolvido nas respostas apresentadas pelas crianças. Esse procedimento permite identificar se o participante responde por exclusão dos estímulos definidos ou por seleção do estímulo novo $\mathrm{S}+$.

$\mathrm{Na}$ fase de linha de base, com nomes e objetos familiares, todos os participantes demonstraram responder sob controle condicional dos estímulos ditados pelo experimentador, ou seja, diante da apresentação de um nome definido, eles de fato procuravam no ambiente pelo brinquedo nomeado.

Nas sondas de exclusão todos os participantes selecionaram um estímulo indefinido nas três oportunidades em que o experimentador ditou cada um dos nomes indefinidos. Esses resultados replicam e estendem, para a situação de brincadeira, aqueles já relatados e que demonstram regularidade e robustez na ocorrência do responder por exclusão (Bates \& Snyder, 1988; Carey \& Bartlett, 1978; Costa et al., 2001; Dixon, 1977; Dixon et al., 1983; Golinkoff et al., 1992; Golinkoff et al., 1994; Markman, 1989; Mervis \& Bertrand, 1994; Oshiro, 2004; Wilkinson \& McIlvane, 1997, entre outros). Mcllvane et al. (2000) apontaram evidências empíricas que demonstram a presença sistemática das duas rotas de controle de estímulos (por exclusão e por seleção) descritas por um ou outro tipo de explicação para a ocorrência de exclusão (mapeamento rápido ou mapeamento simbólico emergente), e a ocorrência conjunta dos dois tipos de controle parece ser o que caracteriza a regularidade do responder por exclusão.

Esse padrão de comportamento tem sido apontado como importante na aquisição da relação nome-objeto, porém ainda faltam evidências de que uma única oportunidade de resposta seja suficiente para o estabelecimento de tal relação. Contrariamente à regularidade nas tentativas de exclusão, resultados de estudos prévios, obtidos com os procedimentos de discriminação condicional realizados no computador, mostraram variabilidade nos testes de verificação de aprendizagem (Costa et al., 2001; Wilkinson \& McIlvane, 1997), o que também foi replicado no presente estudo, sob a condição de brincadeira. Nas sondas de verificação de aprendizagem após uma única tentativa de exclusão, apenas uma de seis participantes apresentou indícios consistentes de aprendizagem, tal como previsto para os três tipos de sondas. Três outros participantes apresentaram indícios de aprendizagem em dois dos três tipos de tentativas, mas a falha em um dos três sugere que a relação nome-objeto não estava tão bem estabelecida a ponto de resistir aos controles concorrentes apresentados na situação de teste. Finalmente, dois dos participantes não apresentaram indícios de aprendizagem (uma ou nenhuma tentativa consistente com a ocorrência de aprendizagem).

Comparando-se os resultados do presente estudo com o de Wilkinson e McIlvane (1997), em ambos a porcentagem de crianças que demonstraram aprendizagem variou nos três tipos de sonda; enquanto a maioria das crianças apresentou 
indícios de aprendizagem nas sondas Tipo 1 e 2 (67\% no presente estudo e 87,5 e 50,0\% em Wilkinson \& McIlvane, 1997), um número bem menor apresentou tais indícios nas sondas de Tipo 3 (33,3\% neste estudo e 25\% no estudo de Wilkinson \& McIlvane). Essa similaridade nos resultados foi encontrada, a despeito de diferenças marcantes nos dois estudos, quanto ao procedimento e quanto à idade das crianças. As crianças do presente estudo eram todas mais novas que as de Wilkinson e McIlvane (1997), uma vez que neste as idades variavam de 25 a 32 meses e naquele a criança mais nova tinha 39 meses e mais velha tinha 60 . De certo modo, apesar da situação de brincadeira não ter assegurado a aprendizagem em uma única tentativa, ela parecer ter favorecido a apresentação de um desempenho que poderia ter sido bem inferior, se prevalecesse a tendência observada no estudo de Wilkinson e McIlvane, (1997), no qual as crianças mais novas tenderam a errar mais. No presente estudo não ocorreu diferenciação tão clara em função da idade: uma das crianças que apresentou apenas um acerto era, também a mais nova, mas o garoto que errou nas três tentativas estava entre os mais velhos deste estudo; por sua vez, a criança que demonstrou aprendizagem só tinha 29 meses. Também não foi necessário empregar o procedimento detalhado e minucioso empregado por aqueles autores para a introdução da máscara: tendo aprendido a colocar e tirar brinquedos nas caixas pequenas, quando o nome de um dos brinquedos definidos era ditado, mas ele não se encontrava disponível sobre o tapete, nenhuma das crianças apresentou dificuldade em procurar por ele nas caixas, até que fosse encontrado (o encontro do brinquedo, por sua vez, parecia ter um evidente efeito reforçador sobre o comportamento de procurar). Os resultados relativamente semelhantes, a despeito das crianças deste estudo serem tão mais novas, podem ser decorrentes de um conjunto de variáveis introduzidas no procedimento, não apenas pelo aspecto lúdico, mas também pela maior variedade de estímulos de escolha, o uso de um procedimento de correção e de conseqüências diferenciais, mesmo nas tentativas de sonda. De um modo geral, portanto, embora não tenha sido suficiente para assegurar aprendizagem, a situação mostrou-se bastante adequada para esse tipo de estudo e poderia ser empregada para a investigação das condições necessárias e suficientes para a ocorrência de aprendizagem da relação nome-objeto por meio de exclusão. Pesquisas futuras poderiam verificar empiricamente, por exemplo, quantas tentativas, relacionando nomes indefinidos a objetos/eventos também indefinidos, seriam necessárias para garantir a aprendizagem; se os dados indicam que uma tentativa de exclusão não é suficiente para a aprendizagem da relação entre nomes indefinidos e seus referentes, seria relevante investigar quantas seriam necessárias para essa aprendizagem. Do mesmo modo, poderia ser relevante investigar efeitos da variação no número de pares ensinados, seja ensinando um único par por vez, ensinando pares cumulativos, um por vez, ou ensinando muitos pares ao mesmo tempo. Explorações de tais processos de aquisição de relações simbólicas têm importantes implicações para ampliar a compreensão da aquisição de linguagem, no que concerne, por exemplo, ao desenvolvi- mento de repertórios de nomeação, de uso de sinônimos, e da organização hierárquica de categorias (sub e supraordenação).

\section{Referências}

Bates, E. (1979). The emergence of symbols: Cognition and communication in infancy. New York: Academic Press.

Bates, E., \& Snyder, L. (1988). Aquisição de um novo conceito aos 20 meses. In R. S. Chapman (Ed.), Processos e distúrbios na aquisição da linguagem (pp. 124-134). Porto Alegre, RS: Artes Médicas.

Carey, S., \& Bartlett, E. (1978). Acquiring a single new word. Papers and Reports on Child Language Development, 15, 17-29.

Carraher, N., \& Spinilo, A. G. (1989). Níveis de significação social e resultados experimentais em psicolingüística. Psicologia: Teoria e Pesquisa, 5(1), 21-30.

Costa, A. R. A., McIlvane, J. W., Wilkinson, K. M., \& de Souza, D. G. (2001). Emergent word-object mapping by children: Further studies using the blank comparison technique. The Psychological Record, 51, 343-355.

Dixon, L. S. (1977). The nature of control by spoken words over visual stimulus selection. Journal of Experimental Analysis of Behavior, 27, 433-442.

Dixon, M. H., Dixon, L. S., \& Spradlin, J. E. (1983). Analysis of individual differences of stimulus control among developmentally disabled children. In K. D. Gadow \& I. Bialer (Eds.), Advances in learning and behavioral disabilities (pp. 85110). New York: JAI Press.

Dunn, L. M., \& Dunn, L. M. (1981). Peabody Picture Vocabulary Test-Revised. Pines, MN: American Guidance Service.

Golinkoff, R. M., Hirsh-Pasek, K., Bailey, L. M., \& Wenger, N. R. (1992). Young children and adults use lexical principles to learn new nouns. Developmental Psychology, 28, 99-108.

Golinkoff, R. M., Mervis, C. B., \& Hirsh-Pasek, K. (1994). Early object labels: The case for a developmental lexical principles framework. Journal of Child Language, 21, 125-155.

Markman, E. M. (1987). How children constrain the possible meaning of words. New York: Cambridge University Press.

Markman, E. M. (1989). Mutual exclusivity. In E. M. Markman (Ed.), Categorization and naming in children: Problems of induction (pp. 187-215). Cambridge, MA: MIT Press.

McIlvane, W. J., Kledaras, J. B., Munson, L. C., King, K. A., de Rose, J. C., \& Stoddard, L. T. (1987). Controlling relations in conditional discrimination and matching by exclusion. Journal of the Experimental Analysis of Behavior, 48, 187-208.

McIlvane, W. J., Wilkinson, K. M., \& de Souza, D. (2000). Origens da exclusão. Temas em Psicologia, 8, 195-203.

Mervis, C. B., \& Bertrand, J. (1994). Acquisition of the novel-namenameless-category (N3C) principle. Child Development, 63, 1646-1662.

Oshiro, C. B. (2004). Exclusão com estímulos visuais e múltiplas relações de condicionalidade na linha de base. Dissertação de Mestrado não-publicada, Programa de Pós-Graduação em Educação Especial, Universidade Federal de São Carlos, SP.

Volterra, V., Bates, E., Benigni, L., Bretherton, I., \& Camaioni, L. (1979). First words in language and action: A qualitative look. In E. Bates (Ed.), The emergence of symbols: Cognition and communication in infancy (pp. 141-222). New York: Academic Press.

Wilkinson, K. M., \& McIlvane, W. J. (1997). Blank comparison analysis of emergent symbolic mapping by young children. Journal of Experimental Child Psychology, 67, 115-130.

Recebido: 03/07/2006

$1^{a}$ revisão: 27/10/2006 Aceite final: 13/12/2006 